\title{
Evaluation of Tourist Decision-Making Process by Eye-Tracking Method - Focused on Methodology Gap and Cross-National Comparison
}

\author{
Zdena Lustigová \\ University of Business in Prague, Prague, Czech Republic \\ Liběna Jarolímková \\ Prague University of Economics and Business, Prague, Czech Republic \\ Jan Žufan \\ University of Business in Prague, Prague, Czech Republic
}

Received: 16 April 2021. Revision received: 26 May 2021. Accepted: 06 June 2021

\begin{abstract}
The dynamic development of information and communication technologies and online marketing in the hospitality and tourism industry changes customer behavior significantly. This article presents the research results focused on measuring the visual attention of potential clients while choosing the hotel online. Eye-tracking-based data collection followed by appropriate statistical analyses was selected to study customers' behaviour and, consequently, judge the effectiveness and impact of used marketing tools. Three scenarios selected for this study covered different clients' segments: 1 /overnight business guests (on the road), 2/weekend package guests (couples), and 3/team-building groups (small companies) and their specific needs. The behaviour of the respondents was monitored in two phases: browsing and deliberation phases. Our study reveals the specifics in Middle and East European consumers' behaviour in both phases, the differences in their priorities, their personal filters used, specifics of their decisionmaking process, etc., compared with Noone \& Robson studies from 2014 and 2016 on US customers. From the methodological point of view, the study reveals the importance of so-called scenarios since it clearly shows that preferences during the browsing phase (e.g. photos of hotels, rooms, bathrooms, its environment, surrounding landscape, etc.) depend on the simulated life situation. The differences in both groups of clients' behaviour and especially in their decision-making process are discussed in the conclusions.
\end{abstract}

Key Words: consumer behaviour, eye-tracking, hospitality, tourism, decision-making process.

JEL Classification: Z33, M31, D12

Reference: Lustigová, Z., Jarolímková, L, Žufan, J. (2021). Evaluation of Tourist Decision-Making Process by Eye-Tracking Method - Focused on Methodology Gap and Cross-National Comparison. Journal of Tourism and Services, 22(12), 89-104. doi: 10.29036/jots.v12i22.258

\section{Introduction}

The hospitality and tourism industry is one of the most important and more visible key drivers of digital transformation. Due to the rapid development in information and communication technologies, innovative business models are dramatically transforming the lodging industry in particular (Cheng, Fu, \& deVreede, 2018; Dickinger, Lalicic, \& Mazanec, 2017), resulting in changing consumer trends and behaviours (Cheng et al., 2019). Based on the dynamic development of online marketing and social media, customer behaviour in hospitality changed significantly. In terms of these changes, it is important to use new and more appropriate methods and tools to measure the effectiveness and impact of used marketing tools. Eye-tracking can be one of them. 


\section{JOURNAL OF TOURISM AND SERVICES}

Issue 12, volume 21, ISSN 1804-5650 (Online)

www.jots.cz

The research was intended to assess the quality of the interaction using eye-tracking measures and different ways of affect recognition, along with task analysis models. Eye-tracking method has been known for a long time and is also used in marketing. However, its use in the field of tourism and hospitality is exceptional. Using the eye-tracking method subconscious preferences can be detected. The research aimed to identify which elements on the hotel website are dominant and attract the attention of potential clients, and to what factors is their attention related to (social group, gender, and type of trip).

This article presents selected questions that will allow a comparison of our results obtained in the open context and the Noone \& Robson studies from 2014 and 2016. Differences in the methodological approach were revealed. This Czech study enriched the method by scenarios, whose importance in focusing attention has been confirmed.

The contribution of the article is to confirm the justification for the use of the eye-tracking method in the field of hospitality. The research has revealed differences in customer behaviour in the US (brand emphasis) and Central Europe (price emphasis). The results will help design information on hotel websites more efficiently.

\section{Literature review}

Consumer behaviour in tourism, due to the fast development and huge sensitivity to external factors, is an often topic of researcher's interest. Scott et al. (2017) and Cohen et al. (2014) published a meta-analysis focused on concepts of customer behaviour in tourism. 519 articles, which focused on customer behavioür key concepts, influences, and research context reviewed in the three leading mainstream tourism journals during the period 2000 - 2012, were identified. Researchers pay attention to changing aspects of customer behaviour very often due to dynamic changes in technologies, the global economy, and society. According to the study (S.A. Cohen et al., 2014), mentioned above, the decisionmaking concept in tourism is a very complex issue within the focus on the process of tourist decisionmaking is needed. Differences in the decision-making process can be influenced by many factors: current stages of the process (pre-visit, on-site, and post-visit), motivations, emotions, cross-culture issues, etc. Scott. et al. (2017) researched the behaviour of hotel customers from Turkey, the Netherlands, Britain, and Israel with the result that there are more differences than similarities. Significant differences were reported particularly between western and Asian cultures in their destination choice behaviour (Kim \& Lee, 2000; You, O'Leary, Morrison \& Hong, 2000), and information search behaviour (Chen \& Gursoy, 2000). The relationship between origin and demographics, preference and attitude variables, was shown in a study by Ozdipciner et al. (2012) where the behaviour of Turkish, European, and Asian tourists was analyzed. Kozak (2002), and Kozak et al. (2003) identified cultural differences in behaviour including destination image, motivation, and satisfaction while visiting Turkey and Spain. Differences in customer behaviour based on collectivist or individualist culture were identified from several studies (Mueller et. al., 2003; Liu \& McClure, 2001; Hui \& Au, 2001).

\subsection{Eye-tracking methods}

Eye-tracking methods are more and more used not only for understanding what factors might influence consumers' decision-making, including colour, amount of text, number of options, and the presence of images but also for understanding affective reactions of users. That is essential to improve the design of systems and to define interactive feedback or adaptation in the system. Generally, eyetracking is capturing eye movements and converting this information into some form of analyzable data. But there are more definitions.

Eye-tracking refers to the use of equipment for observation and documentation of records of a person's unconscious eye movements when looking at a magazine, a shop display, or a website (Wilson, 2012). Venkatraman et al. (2015) consider eye-tracking as one of the neurophysiologic methods with sampling frequency between 60 and $120 \mathrm{~Hz}$ which provides a view into temporal processes. 


\section{JOURNAL OF TOURISM AND SERVICES}

Issue 12, volume 21, ISSN 1804-5650 (Online)

www.jots.cz

Neurophysiologic methods are measures of unconscious automatic reactions to an advertisement (Venkatraman et al., 2015). Eye-tracking is in Venkatraman's opinion also regarded as a direct measure of attention. He also deems eye-tracking an unconscious measure. As it provides insight into the process of the subconscious mind it focuses on contributing a better understanding of the impact of affections and cognition on memory (Vecchiato et al., 2013).

In the year 1908, psychologist Edmund Huey constructed the very first device by which it was possible to observe the object's eye movements during reading. It was a non-transparent plate in which an aperture for the eye pupil has been cut. The plate was connected with a needle which noted the eye movement on a paper. The use of this device was very uncomfortable for the tested object. Furthermore, it involved the anesthesia of the object's eye (Huey, 1918). At the beginning of the study of eye-tracking, mankind did not have the advanced technology we have nowadays. Moreover, the tested objects were not allowed to move their heads. The head was for that reason intentionally consolidated or the objects were forced to hold their heads tightly in one place. It influenced the natural movement of tested objects. The consequence of these unnatural arrangements was that the outcomes of the measurements were distorted (Manhartsberger, 2005). Since the late 90s many companies, mainly advertising agencies, began to use eye-tracking technology for observing reactions of customers when they watched the internet content (e.g.: animations, online advertising). The growing potential of online products and services was the main stimulus for these studies. At that time, when this technology and related research were not available, the majority of the web designers thought that the best design of the internet page is when it looks like printed newspapers.

Starting from the year 2000, eye-tracking technology has continuously evolved, until it spread to almost all areas of life. The companies specialized in eye-tracking are providing a view on human behaviour, for scientific and commercial purposes. Examples of the use of eye-tracking technology are from different areas. E.g. in ophthalmology, they are used for a better understanding of eye movements, prevention and development of media for the treatment of abnormalities; they are also used as a means of communication for people with disabilities who can only use their eyes; they are used in usability tests of websites, computer games, mobile devices; in marketing research, they are used for product tests, etc.

The modern eye-tracking cameras can recognize the position of the pupil and cornea using infrared or near-infrared light that induces corneal reflection. The information processed, the order and duration of these processes can be captured by tracking participants' eye movements when viewing the content (Venkatraman et al., 2015).

Several eye-tracking tools are available, e.g. Eye-tracking visualization; Heat maps; Gaze path plots; Focus maps; and Eye-tracking metrics where belongs Dwell time; Fixation related metrics; Mouseclick related metrics, and Pupil size metric. In the study presented below mostly fixation-related metrics are used.

In the hospitality area, first notions about eye tracking appeared around 2010, and surprisingly not with the main focus to improve online hotel booking. The first hotel applications were published not in professional revues, but on YouTube, and presented the use of eye trackers for the improvement of hotel lobby design, and clients' orientation and navigation. Of course, information on commercial research carried out by private companies, which results have not been published, is not available.

\subsection{Current state of art}

According to Scott et al. article" A review of eye-tracking research in tourism "the limited number of papers indicates that eye-tracking remains relatively understudied in tourism research" (Scott et al., page 7,2017$)$. In the following, the same authors state that researchers focus mainly on two important themes: $1 /$ advertisement perception and $2 /$ consumer attention to marketing information. Technically, according to this study, eye tracking in tourism research has been used mostly to measure the time participants spent looking at stimuli. 


\section{JOURNAL OF TOURISM AND SERVICES}

Issue 12, volume 21, ISSN 1804-5650 (Online)

www.jots.cz

Cornell university journal started to publish the first papers on this topic in 2012. According to the Noone and Robson (2014) eye-tracking study, booking a hotel online involves two major phases: browsing and deliberation. Their study tracked 32 individuals as they worked on selecting a hotel to book found that during browsing, consumers quickly glance at many hotels (sometimes scrolling but often just taking the first screen) as they check the names and prices of available hotels. During this process, consumers apply personal heuristics to identify hotels that warrant further scrutiny.

During the browsing phase consumers fixate primarily on firm-supplied information, including $1 /$ hotel name, $2 /$ images, $3 /$ price, and $4 /$ location, in addition to user $5 /$ ratings. Within the consideration set, consumers fixate most on images, closely followed by firm-provided descriptions. They also fixate on price and room offers, as well as user-generated ratings and reviews.

During the deliberation phase, consumers review more detailed information for the consideration set (usually no more than about seven properties) from which a purchase decision is made.

Pan, Zhang, and Law (2012 and 2014) in "Cornell University quarterly" focused on similar questions, but their major issue was the number of hotels presented on one page. The range was 26 to 50 hotels on the first results pages, which may be too many for a reasonable choice set. According to many studies in cognitive psychology and marketing (too many options are harmful to conversion rates and consumer satisfaction (Iyengar, Wells, and Schwartz 2006; Sethi-Iyengar, Huberman, and Jiang 2004)).

In 2015 Stephani K.A. Robson, senior lecturer at Cornell University School of Hotel Administration presented her research results during a webinar titled "Consumer eye-tracking and revenue management," which was presented jointly by Hospitality Sales and Marketing Association International, Hotel News Now, and HNN's parent company, STR ${ }^{1)}$.

Noone \& Robson studies (2014a, 2014b, 2016) main aim was to improve the existing online booking system of the selected hotel chain and to reveal potential weak spots and confusing points on their booking.com presentation.

The Cornell study kept within the concept that consumers undertake a two-stage process when choosing a product or service. In the online travel environment, consumers "browse" a list of available hotels, apply personal heuristics to identify hotels that warrant further scrutiny, and click through to the detail page, thus forming a "consideration set" (Noone, Robson, 2014, p.1).

Our study accepts this concept and the terms phase 1 and phase 2 are used to describe these particular phases. Phase 1 is according to the above mentioned, defined as the participants activities up to the moment when he/she the first time clicks through the detail page. Since that moment the participants' behaviour changes and we suppose they create their consideration set. This is called phase 2 .

\section{Methodology}

The research was originally intended to assess the quality of the interaction using eye-tracking measures and different ways of affect recognition, along with task analysis models. This article presents selected questions that allow a comparison of our results obtained in the Central European context and the Noone \& Robson studies from 2014 and 2016. The terms phase 1 and phase 2 are used according to the definition mentioned above.

\subsection{Selected research questions}

Measures of reactions to different interface designs are often done in passive situations. Nevertheless, in the context of e-commerce applications, it is important to develop research designs

\footnotetext{
1 See more at http://www.hotelnewsnow.com/article/16098/How-guests-choose-hotels-during-onlinebooking\#sthash.L72aumzr.dpuf
} 


\section{JOURNAL OF TOURISM AND SERVICES}

Issue 12, volume 21, ISSN 1804-5650 (Online)

www.jots.cz

where more interactions are going on. For example, in a web presentation of hotels through GDS, the user actions are constrained by pre-defined steps and areas of visualization. It is, therefore, necessary to follow the user's activities and to study changes in his reactions (recorded face and voice, selfinterpretation) and eye-tracking measures accordingly.

The context in which the user had been at a given moment of the activity path was taken into consideration. Which steps take more cognitive effort and are therefore more stressful? Which parts of the action path were missed or generated more positive or negative feelings? Which were preferred? Which pictures do and do not attract any attention leading to certain actions; e.g. clicking for more information, selecting the hotel, leaving the page, or other kinds of decisions?

In the majority of eye-tracking studies, the authors mention scenarios. But in the case of hospitality and tourism studies, their importance is often underestimated. While Pan et al. (2004) focused just on users behaviour on a webpage, in their following papers they already addressed hospitality and tourism oriented research tasks and questions. Study of Pan \& Law (2013) is focused on online hotel choice while Pan \&Smith (2011) on clients' behaviour in online travel agency offer. The use of scenarios in hospitality and tourism eye tracking research papers is none or very rare ( according Scott et al. (2017) meta-analysis), in comparison to the use of eye tracking in more forensive research areas, where scenarios play an important role (e.g. publications on AirMed and Rescue, Svarekova\&Skultety (2019) training pilots study, and many others). Is not the visual attention of customers and their decision-making significantly influenced by the simulated situation/scenario?

The use of eye-tracking also might help to support or to refuse the hypothesis (often discussed) that consistency is more important in individualistic cultures and that self-congruity therefore has stronger effects (Sung \& Choi, 2012). Furthermore, based on the assumption that individuals from uncertainty-avoiding cultures prefer stability, it was expected that in such cultures, brand-self congruity is more important. But some empirical results (e.g. Matzler et al., 2016) showed the opposite effects and authors tried to retrieve several reasons responsible for their unexpected and surprising finding. Eyetracking method might help to reveal the real behavioural patterns, represented in our case mostly by visual attention, not only self presentation through the questionnaire. The following hypothesis were created on the base of leiterature review and research questions mentioned above.

\subsection{Hypotheses}

H01: The visual attention to different screen items while choosing the hotel online does not depend on the scenario at any phase (browsing/consideration/...)

H02: There is no difference in the visual attention between the group of American and Middle/East European customers while choosing the hotel online at any phase (browsing/consideration/...).

\subsection{Research tools}

A Tobii eye-tracking system ${ }^{2}$ was used along with the system of the tasks description, questionnaires and post-action interviews. Screen interactions and navigation activity were also recorded to integrate the task analysis dimension. The voice and face records were used as an additional information source.

Measures were corrected for baseline and areas of fixation where defined. The data collected were analyzed to highlight affective reactions: descriptive statistics for the different zones of interest; the

\footnotetext{
${ }^{2}$ http://www.tobii.com
} 


\section{JOURNAL OF TOURISM AND SERVICES}

Issue 12, volume 21, ISSN 1804-5650 (Online)

www.jots.cz

relation between clients' comments and eye-tracking measures; the relation between previous preferences and affective reactions; the correlation between reactions and subjective measures of affections, etc.

\subsection{Research design}

SSRD (single sample/small sample research designs) as a rigorous, scientific methodology was used to define basic principles of behaviour and establish evidence-based practices. Since the methodology was first operationalized over 40 years ago (by Sidman in 1960), a long and productive history exists in which SSRD has provided useful information for different fields of interest.

These designs are used primarily to evaluate the effect of a variety of interventions in applied research, extensively in the experimental analysis of behaviour and applied behaviour analysis with both human and non-human participants. SSRD designs are often preferred for their high flexibility and sensitivity to individual differences in response to intervention effects (Thomson, 1986).

Generally Eye-tracking studies use relatively few participants, similar to neurophysics or physiology studies (Goldberg \& Wichansky, 2002). A meta-analysis of eye-tracking research on differences between experts and novices found an average cell size of 11 (Scott et al. (2017)).

In our case, the SSRD design was chosen because these designs allow researchers to compare each participant's performance with his/her other performances across various settings (Tankersley, Harjusola-Webb, and Landrum, 2008). Thus, this method allowed us to evaluate the effectiveness of different settings (way of advertisement, pictures presented, etc.) in 3 different simulated life situations (scenarios) on our participants and helped us to make decisions about which of these settings are more or less effective and efficient.

Fixation was measured because fixations are an excellent measure of visual attention. Fixation is a cluster of gaze points. Gaze points generally show what the eyes are looking at. The number of gaze points depends on the eye tracker sampling rate. According to Farnsworth (2020) if a series of gaze points is very close - in time and/or space - this gaze cluster constitutes a fixation, denoting a period where the eyes are locked towards an object.

\subsection{Sample description}

All participants (ten, five women and five men), were adults between 20 and 60; two aged 20 to 30, one 31 to 40, two 41 to 50, and four 51 to 60. All participants were Middle Europeans (Czech, Germain, Polish, Austrian origin), operating fluently at least two languages, mostly English as their first foreign language. This is an important fact since the participants' fluency in English (the language of the most frequently used reservation systems) allows the behavioural patterns comparability and does not create any bias.

All of them have completed at least secondary education (according to statistics, people with higher education travel more frequently and often stay in hotels, also use more Internet and mobile applications). All educational backgrounds were represented, from humanities to science, technology, and economics.

All participants declared their positive relationship to travel, all of them were frequent travellers (within a European context, that differs from the US context mostly in the number of foreign countries visited yearly). The older generation's preferences were to be fully served, especially in the booking and check-in phase, the younger (especially men) did not mind online-based self-service. However, these limitations were not technical, but psychological. Thus they did not create any bias.

The research was carried out in the period February-March 2019. 


\section{JOURNAL OF TOURISM AND SERVICES}

Issue 12, volume 21, ISSN 1804-5650 (Online)

www.jots.cz

\section{Results}

\subsection{Questionnaire data analysis}

The most applicable results and recommendations from our research rose from the part, called scenarios or "life situations". This part of the eye-tracking study was commercial, based on a contract. Participants could choose the task that best suits their age, lifestyle, experience, etc.

1. Sleep on the way (Germany-Prague): Driving from Germany. Around $8 \mathrm{pm}$ you feel tired and decide not to try fate and to find a place for a sleepover. Start looking for accommodation (the location was specified).

2. Team building: You are responsible for teambuilding activities in your business. You want to spend about 2-3 days outside Prague. Finish the task. (The location was specified).

3. Stay Package: Your parents always want to spend a couple of days in the Sumava mountains region, but also in the town (they are more in cafes than hiking). Buy them a stay package.

The results showed, what kind of images presented on the webpage, leads to a certain action, e.g. clicking or leaving, even if not all participants, while questioned, admitted that. It also presented general differences in hotel selection decision making between men and women, the different importance of certain colour scheme and content of presented imagines, and different filter setup for the same life situation.

None woman selected "the sleep on the way" life situation, even if all of them were frequent travellers and drivers. It helped to specify the target group for "one-night sleepover" and target them with "man preferably" attractive pictures, like details of the breakfast table and room detail with a bed and a lit night lamp.

Table 1. Summary participants profiles

\begin{tabular}{|c|c|c|c|c|c|c|c|c|c|}
\hline \multicolumn{3}{|c|}{ Personal info } & \multicolumn{2}{|c|}{ Education } & \multicolumn{5}{|c|}{ Travelling and accommodation preferences } \\
\hline$\Leftrightarrow$ & $\begin{array}{l}\frac{\vec{D}}{\tilde{E}} \\
\tilde{D} \\
0\end{array}$ & 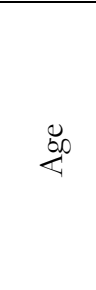 & 胥 & 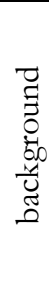 & 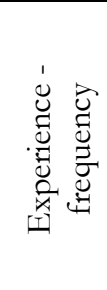 & 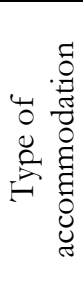 & 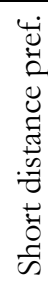 & 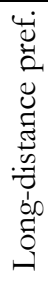 & 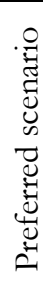 \\
\hline ID1 & $\mathrm{F}$ & $31-40$ & 4 & 2 & 3 & 1 & 4 & 1 & 3 \\
\hline ID2 & $\mathrm{F}$ & $51-$ & 4 & 2 & 1 & 1 & 1 & 1 & 3 \\
\hline ID3 & M & $31-40$ & 4 & 3 & 1 & 1 & 5 & 1 & 1 \\
\hline ID4 & M & $41-50$ & 3 & 3 & 5 & 1 & 1 & 1 & 2 \\
\hline ID5 & $\mathrm{M}$ & $20-30$ & 3 & 4 & 4 & 1 & 2 & 1 & 1 \\
\hline ID6 & $\mathrm{F}$ & $41-50$ & 3 & 4 & 3 & 1 & 5 & 1 & 3 \\
\hline ID7 & $\mathrm{F}$ & $51-$ & 4 & 1 & 5 & 2 & 2 & 1 & 3 \\
\hline ID8 & M & $51-$ & 4 & 2 & 1 & 2 & 2 & 1 & 1 \\
\hline ID9 & F & $20-30$ & 2 & 1 & 5 & 3 & 4 & 2 & 3 \\
\hline ID10 & M & $31-40$ & 3 & 2 & 5 & 1 & 2 & 1 & 1 \\
\hline
\end{tabular}

In the categorical variable "Education level" 2 means secondary school education, 3 means university degree, and 4 means $\mathrm{PhD}$ and higher. "Education background" variable 1 means economics, 2 means informatics, 3 means social sciences and 4 science. 


\section{JOURNAL OF TOURISM AND SERVICES}

Issue 12, volume 21, ISSN 1804-5650 (Online)

www.jots.cz

The information about the experience of travellers is under the variable "Experience-frequency" consisting of 5 categories. The basic characteristics of traveller are described with four "preference" variables, the first one describing the preferred type of accommodation (where 1 means hotel, 2 means pension or $\mathrm{B} \& \mathrm{~B}, 3$ means $\mathrm{Air} B \mathrm{~B} \mathrm{~B}$ ), the second and third the preferred way of travelling on both short and long distances, and also the preferred scenario (three different scenarios mentioned above).

\subsection{Eye-tracking data analysis}

The design of the study was based on the experience that scenarios are a significant factor influencing human reactions. 3 scenarios were prepared:

1. Sleep on the way

2. Team building

3. Stay Package

(More detailed description see above).

Scenario 1 (overnight stay, business, single) was preferred mostly by men. When asked to fullfill the task, women did not pay too much attention, which would cause the thread to internal validity, so their results are not included in the above chart. The interview and questionnaires revealed that women would prefer an overnight drive if happened to be in the described situation. The second preferred solution was to pick up the closest brand name big hotel with all-night service. The price, reviews, pictures, etc. in this special (for them very stressful) situation did not play any role.

Graph 1. Comparison of browsing and consideration phase visual attention / Average fixations time (relative) by information type.

Relative diameter of fixation circle

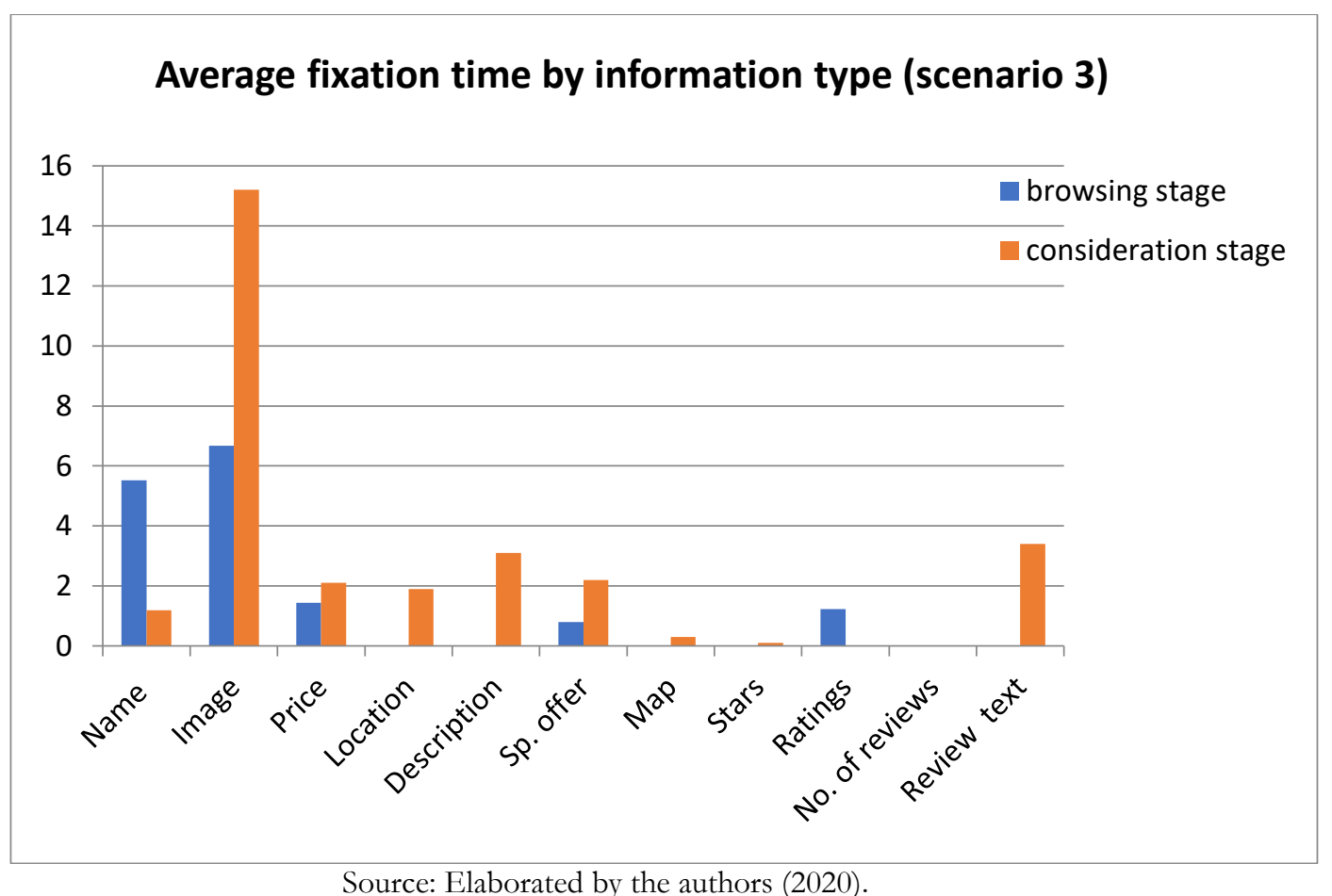

Source: Elaborated by the authors (2020). 


\section{JOURNAL OF TOURISM AND SERVICES}

Issue 12, volume 21, ISSN 1804-5650 (Online)

www.jots.cz

Table 2. Rank according to the sum of all fixations in the consideration phase / Comparison of scenarios.

\begin{tabular}{|c|l|c|c|}
\hline $\begin{array}{c}\text { Item } \\
\text { No }\end{array}$ & Item & $\begin{array}{c}\text { Rank according to the sum of all } \\
\text { fixations (consideration phase) }\end{array}$ \\
\hline & & $\begin{array}{c}\text { scenario } \\
1\end{array}$ & $\begin{array}{c}\text { scenario } \\
3\end{array}$ \\
\hline 1 & Name & 8 & 7 \\
\hline 2 & Image & 1 & 1 \\
\hline 3 & Price & 7 & 5 \\
\hline 4 & Location & 5 & 4 \\
\hline 5 & Description & 2 & 3 \\
\hline 6 & Map & 4 & 10 \\
\hline 7 & Star & 10 & 7 \\
\hline 8 & Ratings & 6 & 6 \\
\hline 9 & No of reviews & 9 & 2 \\
\hline 10 & Review text & 3 & 8 \\
\hline \multicolumn{4}{|c|}{ Source: Elaborated by the authors (2020). } \\
\hline
\end{tabular}

The hypothesis (H01) was that the visual attention while choosing the hotel does not depend on the scenario (since other authors in their researches did not mention the scenarios).

For testing the hypothesis was used the Mann-Whitney U test. The calculated U-value is 48. The critical value of $U$ at $p<0.05$ is 23 for two-tailed alternatives. The $z$-score is 0.11339 . The $p$-value is 0.9124 . Therefore, the null hypothesis was refused. Both test results support the alternative one. In other words: In both scenarios, the maximal visual attention was dedicated to images, but the visual attention paid to the rest of the items differs significantly according to the scenario.

Similarly, the null hypothesis for the browsing phase had to be rejected. At the browsing phase, customer behaviour was so different in different scenarios that no statistical evidence was needed. For example, in scenario 1 they used filters (for the overnight reception desk, etc.), while in scenario 3 the filtering tools were used just by one participant.

In both, 1 and 3 scenarios, during both phases (browsing, consideration), the maximal visual attention was paid to images. But the behaviour differs.

In scenario 1 participants' selection of hotels in the consideration phase was mostly influenced by convenience (on the way, overnight desk, easily accessible parking, etc.). Then, within the consideration phase, they paid a lot of attention to images and decided mostly emotionally (bed highlighted by a lamp, plate with breakfast, see graph No 2).

Chosen hotel was always the one that offered at least one of the most attractive images, e.g. detail of bed with white, clean, and visibly soft pillows, highlighted by night lamp and nicely decorated full breakfast plate.

Within scenario 3 participants (mostly women) have paid attention to images since the beginning (browsing phase). Hotels selected to the consideration phase were always presented with nice artistic pictures, with well-balanced colours and scenes. Hotels presented just by building picture were neglected. None of them was considered. Participants read the textual information very briefly or not at all. The most important factor for the selection into the consideration set was an image. 
Graph 2. Average fixation time (relative) by type of image / Consideration set, chosen hotel included

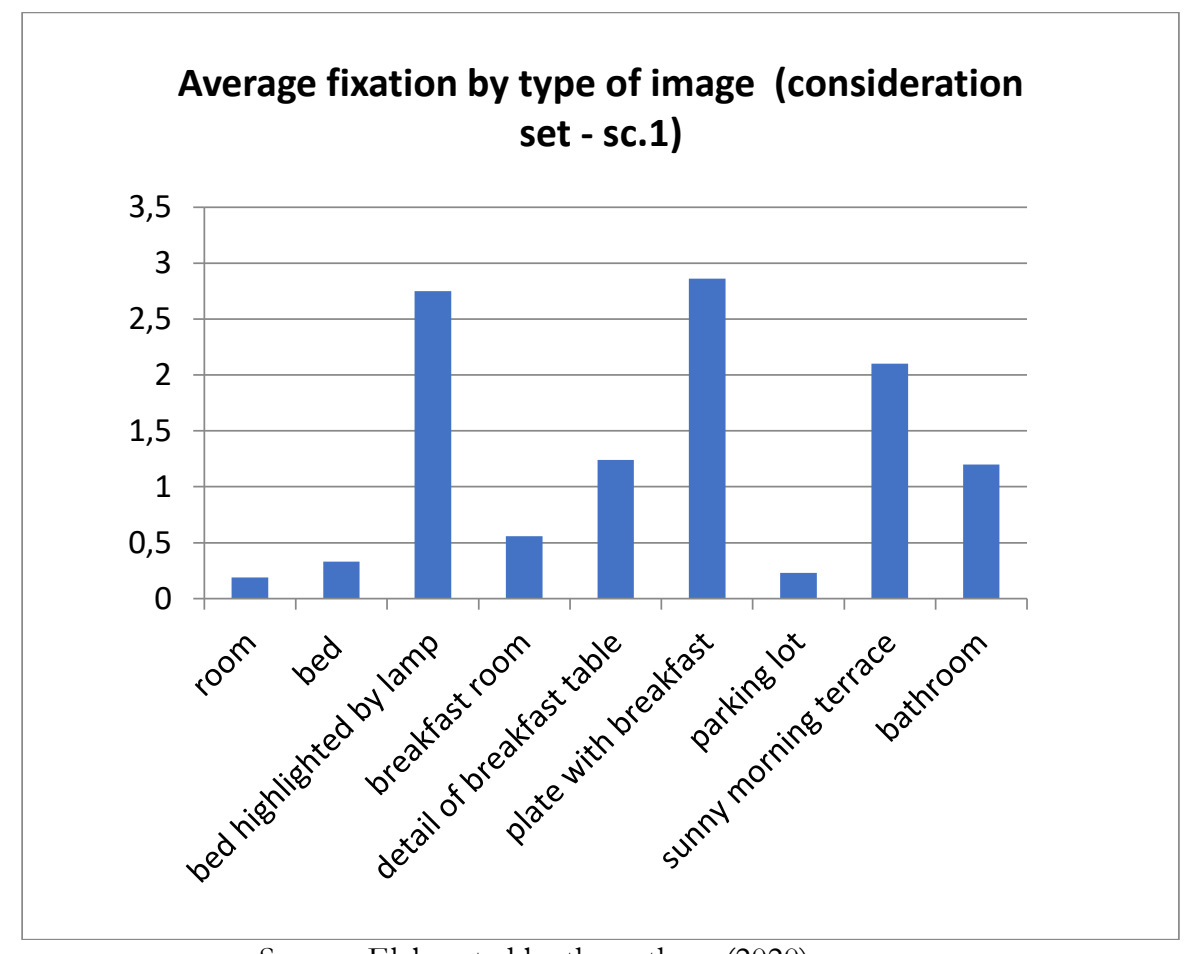

Source: Elaborated by the authors (2020).

Graph 3. Average fixation time (relative) by type of image / Browsing set, chosen hotel included

\section{Average fixation by type of image (browsing} phase - sc. 3)

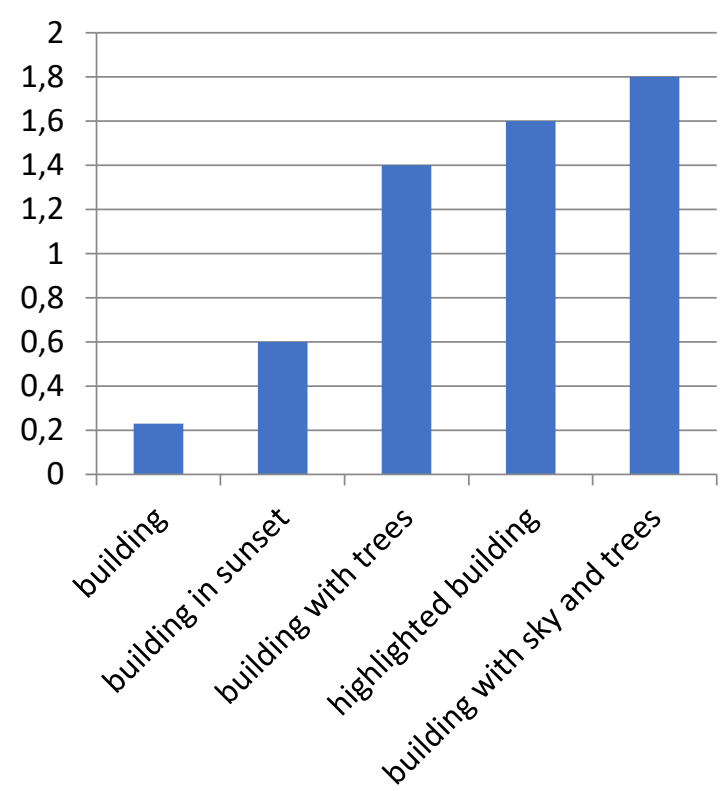

Source: Elaborated by the authors (2020). 


\section{JOURNAL OF TOURISM AND SERVICES}

Issue 12, volume 21, ISSN 1804-5650 (Online)

www.jots.cz

\subsection{Findings}

The most important finding of this presented study suggests, that consumers' shopping behaviour and priorities, filters used, the tracked paths, and the length of fixations depend on the scenario (simulated life situation). Also, the importance of the physical appearance of a hotel, rooms, bathrooms, its environment, landscape surrounding, etc., depends on the scenario. 3 scenarios selected for this study covered the clients' segment according to the description - overnight business guest (on the way), weekend package guests (couples), and groups for team building (small companies).

The fixation times are in case of scenario 1 and scenario 3 almost incomparable.

On the other side in the case of scenario 3, the browsing phase was longer. Consumers paid attention to the hotel's physical appearance and landscape surroundings. In the consideration set, just hotels with nice (romantic) pictures appeared. There has to be a tree and blue sky (possibly with white clouds), or nice evening lights reflected in water, if possible.

\subsection{Comparison of the behaviour of Middle European and US customers}

For testing the hypothesis H02 again the Mann-Whitney U test was used.

Images were in the centre of customers' interest in our study as well as Noone and Robson studies from 2014 and 2016. Unlike Noone and Robson in their studies (2014a, 2014b, 2016), who measured the average number of fixation, we measured fixation according to the definition mentioned above. Generally, our Middle European participants, in both scenarios 1 and 3, were not so interested in descriptions.

On the other side, they paid more attention to "stars" but checked ratings from other users less than Noone and Robson studies (2014a, 2014b, 2016) found (even if it is ranked in the same position 3). Some of them read one or two reviews, usually connected to a selected hotel. Reviews did not play any role in the selection, but all our participants during the interview admitted, that in the case of different kinds of accommodation $(\mathrm{B} \& \mathrm{~B}, \mathrm{Air} \mathrm{BnB})$ the customers' reviews would play a more important role in their decision making process.

Middle and East European travellers do not pay much attention to brand names, and they are rarely members of hotel loyalty programs.

All together the comparison looks like the following:

Table 3. Rank according to the sum of fixations - consideration phase / Comparison of Noone Robson and our results

\begin{tabular}{|c|c|c|c|c|}
\hline Item No & Item & $\begin{array}{c}\text { Rank according } \\
\text { to the average } \\
\text { number of } \\
\text { fixation for the } \\
\text { chosen hotel }\end{array}$ & & $\begin{array}{c}\text { Rank according } \\
\text { to the overall } \\
\text { length of fixation } \\
\text { for the chosen } \\
\text { hotel }\end{array}$ \\
\hline & & $\begin{array}{c}\text { Noone-Robson } \\
\text { study (US) }\end{array}$ & & $\begin{array}{c}\text { Lustigova study } \\
\text { (Middle Europe) }\end{array}$ \\
\hline 1 & Name & $7(5)$ & & 7 \\
\hline 2 & Image & 1 & & 1 \\
\hline 3 & Price & 6 & & non-applicable \\
\hline 4 & Location & 9 & & non-applicable \\
\hline 5 & Description & 2 & & 5 \\
\hline 6 & Offer & 5 & & 4 \\
\hline 7 & Map & $13(8)$ & & non-applicable \\
\hline 8 & Star & $12(7)$ & & 4 \\
\hline
\end{tabular}




\section{JOURNAL OF TOURISM AND SERVICES}

Issue 12, volume 21, ISSN 1804-5650 (Online)

www.jots.cz

\begin{tabular}{|c|c|c|c|c|}
\hline 9 & Ratings & 3 & & 3 \\
\hline 10 & no of reviews & $10(6)$ & & 8 \\
\hline 11 & Review text & 4 & & 6 \\
\hline 12 & Reviewer profile & 11 & & non-applicable \\
\hline 13 & User image & 14 & & non-applicable \\
\hline 14 & Rank & 8 & & non-applicable \\
\hline
\end{tabular}

Source: Elaborated by the authors (2020).

Item No 3 (price) is not applicable, since the situation was simulated (as well as in the case of Noone Robson study, where should be non-applicable as well). Czech participants, who were interviewed after the end of the eye-tracking part of our research, admitted, that in a real-life situation, they would pay more attention to the price, and it might influence their final selection. No 4 (location) was predefined by scenarios.

Items No 12 (reviewer profile), No 13 (user image), and No 14 (rank) were not taken into consideration at all (by participants of this research). No 12 and 13 were on the tail of the Noone Robson study scale as well, but No 14 (Rank) got order 8, which means somewhere in the middle of attention.

It was compared whether, for the items studied in both studies, groups of participants paid the same attention to the same items. Both participant groups (Noon\&Robson study, Lustigova study) focus No 1 were images, but the attention paid to the rest of the items differs significantly.

The Mann-Whitney U test was used for testing the hypothesis. The calculated U-value is 32 . The critical value of $U$ at $p<0.05$ is 13 . Since the approximation to the form of the normal distribution becomes less robust at sample sizes smaller than 10 (our case), is appropriate to use also the Z-value calculation. The z-score is 0.05251 . The p-value is 0.96012 . Therefore, the null hypothesis was refused. Both test results support the alternative one.

\section{Discussion}

Comparison of the results of the current study with the results of the Noone\&Robson studies showed some differences. The reasons for differences may be factual or methodological.

Unclearly described methodology in many studies does not allow repeatability and thus the realistic comparison. For example, the number of fixation (Noone and Robson studies (2014a, 2014b, 2016) used, is not exactly defined within their study and thus disables exact comparison on the metrics and leads to the use of statistical methods for ordinal scales.

Neither number of fixation, either the summarized length of fixation on a certain object/item does not reflect exactly the importance of the item for the customers. The price might be checked once and the decision is made, while certain pictures might attract attention for a longer time. Also according to our interviewed participants, the repeated visual attention to the name of the hotel was not because they were attracted by it, but because they wanted to be sure that it is the one, they already have seen/considered/etc.

Also the methodology concerning the significance of differences in visual attention and decision making processes between US customers and Middle and East European customers is not unified and different mothodological approaches are not comparable. Different preferences (depending on the language background) are confirmed many authors, e.g. by Johann's finding (2017). According to her research English-speaking tourists, in addition to features, shared by all respondents, had some different preferences, especially concerning social aspects (entertainment, communication in English, social contacts, etc.), while choosing the destination and the travel program.

Mariani, Borghi, and Okumus (2020) point out the fact that the origin of customers reflects also in the choice of destination, while the evaluation of services depends more on the language used by both 


\section{JOURNAL OF TOURISM AND SERVICES}

Issue 12, volume 21, ISSN 1804-5650 (Online)

www.jots.cz

sides. Our findings partially confirm the results of some authors, while they contradict others. The methodological issue, mentioned above, is the critical one. It undoubtedly deserves deeper attention and the authors will focus on it in their future work.

\section{Conclusions}

According to our results, the visual attention to different screen items while choosing the hotel online depends significantly on the scenario at each phase (browsing/consideration). In the NooneRobson studies mentioned above, the scenarios are not described neither used.

The importance of scenarios was proved in many other areas (as mentioned above) and our study proved its importance in studies of customers' behaviour as well.

Theoretical implications of this study relate to the specification of methodology suitable for use in both hospitality and tourism sectors. We again proved, that scenarios (simulated life situations) are important in the consumer decision-making process. People's affective reactions depend on them; they solve the problem differently depending on the scenario.

Within the long term discussion about the differencies in the behavioural patterns in both phases of decision making process our results do not support Matzler's findings (Matzler et al., 2016) but those of his oponnents. Our comparison, based on eyetracking studies of Noone and Robson and ours, with similar methodology and sampling, proved statistically significant difference in visual attention and decision making processes between US customers (known for their highest individualism score IDV of 91) and Middle and East European customers (Poland, Czech Republic, Austria with IDVs of 60, 58 and $55)$.

New research questions also emerge from this research. It would be appropriate to measure both information and cognitive loads and thus reveal potential problems hidden there. Which steps take more cognitive effort and are therefore are more stressful? Which parts of the screen need higher information load and thus provoke excitement or anger? A detailed analysis of the information needs to be performed to answer the questions of clarity, readability, logical arrangement, the ambiguity of content, graphics, design, layout, visualization of information.

\section{References}

1. Bayarsaikhan, Tsolmon \& Kim, Sang-Tae \& Gim, Tommy. (2020). International tourists' destination choice differences according to Plog's personality types: analyzing the case of Mongolia based on the recreation opportunity spectrum. International Journal of Urban Sciences, 24. 1-31. 10.1080/12265934.2020.1771195.

2. Bebko, C., Sciulli, L. M., \& Bhagat, P. (2014). Using eye tracking to assess the impact of advertising appeals on donor behavior. Journal of Nonprofit \& Public Sector Marketing, 26(4), 354371. doi:10.1080/10495142.2014.965073.

3. Chen, S. J., \& Gursoy, D. (2000). Cross-cultural comparison of the information sources used by first-time and repeat travelers and its marketing implications. International Journal of Hospitality Management, 19 pp. 191-203.

4. Cheng, X., Fu, S., de Vreede, G.J. (2018). A mixed method investigation of sharing economy driven car-hailing services: Online and offline perspectives. International Journal of Information Management, 41 (2018), pp. 57-64.

5. Chua, H., Boland, J., \& Nisbett, R. (2005). Cultural variation in eye movements during scene perception. Proceedings of the National Academy of Sciences of the United States of America, 102(35), 12629-12633. 


\section{JOURNAL OF TOURISM AND SERVICES}

Issue 12, volume 21, ISSN 1804-5650 (Online)

www.jots.cz

6. Cohen, S. C., Prayag, G., \& Moital, M. (2014). Consumer behaviour in tourism: Concepts, influences and opportunities. Current Issues in Tourism, 17:10, 872-909. doi:10.1080/13683500.2013.850064

7. Dickinger, A., Lalicic, L. \& Mazanec, J. (2017). Exploring the generalizability of discriminant word items and latent topics in online tourist reviews. International Journal of Contemporary Hospitality Management, 29 (2), pp. 803-816.

8. Farnsworth, B. (2020). 10 Most Used Eye Tracking Metrics and Terms. iMotions A/S. Online, retrieved 01/15/2021 from: https://imotions.com/blog/7-terms-metrics-eye-tracking/).

9. Goldberg, Joseph \& Stimson, Mark \& Lewenstein, Marion \& Scott, Neil \& Wichansky, Anna. (2002). Eye tracking in web search tasks. 51. 10.1145/507079.507082.

10. Huey, E. (1918). The history and pedagogy of reading. New York: Macmillan Co., ISBN 9780548803219.

11. Hui, M. K., \& au, K. (2001). Justice perceptions of complaint - handling: a cross-cultural comparison between PRC and Canadian customers. Journal of Business Research, 32, pp. 165-173.

12. Johann, Maria. (2017). Cross-cultural Differences in Tourism Product Preferences.

13. Kim, C. \& Lee, S. (2000). Understanding the cultural differences in tourist motivation between Anglo-American and Japanese tourist, Journal of Travel and Tourism Marketing, 9 (2), pp. 153170 In Yuksel, A., Kilinc U., K., \& Yuksel, F. (2006) Cross-national analysis of hotel customers' attitudes toward complaining and their complaining behaviors, Tourism Management, 27(1), pp. 11-24, ISSN 0261-5177.

14. Kozak, M. (2002). Comparative analysis of tourist motivations by nationality and destinations. Tourism anagement, 23 (3), pp. $221-232$.

15. Kozak, M., Bigné, E., González, A. \& Andreu, L. (2003). Cross-cultural behavior research in tourism: a case study on destination image. Tourism Analysis, Vol. 8, pp. 253-257.

16. Liu, R. R. \& McClure, P. (2001). Recognizing cross-cultural differences in consumer complaint ehavior and intentions. Journal of Consumer Marketing, 18(1), pp. 54-74.

17. Manhartsberger, M. and Zellhofer N. (2005). Eye tracking in usability research: What users really see. In: Empowering Software Quality: How Can Usability Engineering Reach These Goals?. Vienna: OCG publication.

18. Mariani, Marcello \& Borghi, Matteo \& Okumus, Fevzi. (2020). Unravelling the effects of cultural differences in the online appraisal of hospitality and tourism services. International Journal of Hospitality Management. 90. 102606. 10.1016/j.ijhm.2020.102606.

19. Matzler, Kurt \& Strobl, Andreas \& Stokburger-Sauer, Nicola \& Bobovnicky, Artur \& Bauer, Florian. (2016). Brand personality and culture: The role of cultural differences on the impact of brand personality perceptions on tourists' visit intentions. Tourism Management. 52. 507-520. 10.1016/j.tourman.2015.07.017.

20. Mueller, R. D., Palmer, A., Mack, R. \& McMullan, R. (2003). Service in the Restaurant Industry: An American and Irish Comparison of Service Failures and Recovery Strategies. International Journal of Hospitality Management, 22, 395-418.

21. Noone, B., \& Robson, S. K. A. (2014a). Show Me What You See, Tell Me What You Think: Using Eye Tracking for Hospitality Research. Cornell Hospitality Report, 14(17), pp. 4-12. https://ecommons.cornell.edu/handle/1813/71117

22. Noone, B., \& Robson, S. K. A. (2016). Understanding Consumers' Inferences from Price and Nonprice Information in the Online Lodging Purchase Decision. Cornell Hospitality Research Summit Special Issue, pp. 97-248. Doi https://doi.org/10.1287/serv.2016.0141 


\section{JOURNAL OF TOURISM AND SERVICES}

Issue 12, volume 21, ISSN 1804-5650 (Online)

www.jots.cz

23. Noone, B., \& Robson, S. K. A. (2014b). Using eye tracking to obtain a deeper understanding of what drives online hotel choice. Cornell Hospitality Report, 14(18), pp. 6-16.

https://ecommons.cornell.edu/bitstream/handle/1813/71105/Noone_202014_20Using_20ey

e_20tracking.pdf?sequence $=1$ \&isAllowed $=y$

24. Ozdipciner, N. S., Li, X. \& Uysal, M. (2012). Cross-cultural differences in purchase decisionmaking criteria. International Journal of Culture, Tourism and Hospitality Research, Vol. 6/1, pp. 34-43.

25. Pan, B., Hembrooke, H., Gay, G. K., Granka, L., Feusner, M., \& Newman, J. (2004). The determinants of web page viewing behavior: an eye-tracking study. Paper presented at the Proceedings of the 2004 symposium on Eye tracking research \& applications, New York.

26. Pan, B., Zhang, L., \& Smith, K. (2011). A mixed-method study of user behavior and usability on an online travel agency. Information Technology \& Tourism, 13(4), 353-364.

27. Pan, B., Zhang, L., \& Law, R. (2013). The complex matter of online hotel choice. Cornell Hospitality Quarterly, 54(1), 74-83.

28. Scott, N., Zhang, R., Le, D. \& Moyle, B. (2017). A review of eye-tracking research in tourism. Current Issues in Tourism, 22:10, pp. 1244-1261, DOI: 10.1080/13683500.2017.1367367

29. Turner, Lindsay \& Reisinger, Y \& McQuilken, Lisa. (2002). How Cultural Differences Cause Dimensions of Tourism Satisfaction. Journal of Travel \& Tourism Marketing. 11. 79-101. 10.1300/J073v11n01_05.

30. Vecchiato, G., Susac, A., Margeti, S., De Vico Fallani, F., Maglione, A. G., Supek, S., Planinic, M. and Babiloni, F. (2013). High-Resolution EEG Analysis of Power Spectral Density Maps and Coherence Networks in a Proportional Reasoning Task. Brain Topography, 26(2).

31. Venkatraman, V., Dimoka, A., Pavlou, P. A., Vo, K., Hampton, W., Bollinger, B., Hershfield, H. E., Ishihara, M. AND Winer, R. S. (2015). Predicting Advertising Success Beyond

Traditional Measures: New Insights from Neurophysiological Methods and Market Response Modeling. Journal of Marketing Research, 52(4).

32. Wilson, A. (2012). Marketing research; An Integrated Approach. 3rd ed. Harlow: Financial Times Prentice Hall, ISBN 978-0-273-71870-3.

33. Xu, Xueyan \& Scott, Noel \& Gao, Jun. (2017). Cultural influences on viewing tourism advertising: An eye-tracking study comparing Chinese and Australian tourists. JOURNAL OF TOURISM AND SERVICES. Volume 8, Issue 14, pp. 30-46.

34. Xusen Cheng, Shixuan Fu, Jianshan Sun, Anil Bilgihan, Fevzi Okumus. (2019). An investigation on online reviews in sharing economy driven hospitality platforms: A viewpoint of trust. Tourism Management, Volume 71, 2019, pp. 366-377, ISSN 0261-5177.

35. You, X., O'Leary, J., Morrison, A. \& Hong, G. (2000). A cross-cultural comparison of travel push and pull factors: United Kingdom versus Japan. International Journal of Hospitality and Tourism Administration, 12 pp. 1-25 In Yuksel, A., Kilinc U., K., \& Yuksel, F. (2006) Crossnational analysis of hotel customers' attitudes toward complaining and their complaining behaviors, Tourism Management, 27(1), pp. 11-24, ISSN 0261-5177.

\section{Brief description of Author/Authors:}

\section{doc. RNDr. Zdena Lustigová, CSc.}

ORCID ID: https://orcid.org/0000-0001-8674-5393

Department of Information Technology and Analytical Methods, University of Business in Prague, Spálená 76/14, Praha 1 - Nové Město, 110 00, Czech Republic, www.vso.cz, lustigova@vso-praha.eu. Associated professor Zdena Lustigova devoted part of her life to human-computer interaction research and the use of physiological and neurophysiological measurement (including eye-tracking) for automated feedback in different areas, e.g. education, marketing and many others. 


\section{Ing. Liběna Jarolímková, Ph.D.}

ORCID ID: https://orcid.org/0000-0001-8502-5220

Department of Tourism, Faculty of International Relations, Prague University of Economics and Business, W. Churchill sq. 4, Praha 3, 130 67, Czech Republic, www.vse.cz, jaro@vse.cz. Liběna Jarolímková is an assistant professor, head of the Department of Tourism, member of AIEST. Her main fields of work are tourism market trends and interpretation of nature and cultural heritage in tourism. She participates in international projects for the modernization of tourism expert education.

\section{RNDr. Jan Žufan, Ph.D., MBA}

ORCID ID: https://orcid.org/0000-0001-9031-5791

Department of Management, University of Business in Prague, Spálená 76/14, Praha 1 - Nové Město, 110 00, Czech Republic, www.vso.cz, zufan@vso-praha.eu. Jan Žufan is the Chancellor of the University and a member of the Department of Management. He deals with issues of management of tourism organizations. His main areas of interest are human resources in tourism, HR marketing and the use of data in HR management. 